\title{
Convivencia y vigilancia: cruising y producción del espacio público
}

\author{
Coexistence and vigilance: cruising and production of public \\ space
}

LUIS PERIÁÑEZ LLORENTE (Universidad Complutense de Madrid)

Artículo recibido: 1 de febrero de 2019

Solicitud de revisión: 5 de marzo de 2019

Artículo aceptado: 10 de abril de 2019

Periáñez Llorente, Luis (2020). Convivencia y vigilancia: cruising y producción del espacio público. Recerca. Revista de Pensament i Análisi, 25 (2), pp. 73-94.

\section{Resumen}

Nos ocupamos aquí de cómo se produce y comprende la publicidad del espacio público y de cómo dicha producción y comprensión repercute normativa y performativamente sobre los usuarios de aquel. El enfoque que hemos escogido pretende comentar estos aspectos con la ayuda de las etnografías que se han venido realizando en los últimos tiempos sobre el cruising, por cuanto esta actividad, que implica una apropiación furtiva de determinados espacios públicos para el desarrollo de actividades sexuales anónimas entre hombres, ofrece un observatorio privilegiado del desfase entre el espacio público como dispositivo performativo y los agentes, que no siempre son meramente moldeados por tales dispositivos. Encontramos en esta práctica una ventana privilegiada para el análisis de la forma en que lo público y lo privado son construidos espacial y conceptualmente en la dialéctica entre marcos morales y prácticas subjetivas.

Palabras clave: heteronormatividad, espacio público, cruising, dispositivo.

\section{Abstract}

We deal here with how public space publicity is produced and understood, and how such production and understanding have a normative and performative impact on the users of that space. The approach we have chosen intends to co-ordinate these aspects with the help of the ethnographies that have been carried out in recent times on cruising, as this activity, which implies a furtive appropriation of certain public spaces for the development of anonymous sexual activities among men, offers a privileged observatory of the gap between public space as a performative device and agents, which are not always merely molded by such devices. We find in this practice an optimal window for the analysis of the 
way in which the public and the private are construed spatially and conceptually in the dialectic between moral frameworks and subjective practices.

Key Words: heteronormativity, public space, cruising, device.

\section{INTRODUCCIÓN}

En el presente ensayo nos haremos cargo del espacio público. Su especificidad y el interés de su análisis viene dado, entre otros motivos, por su importancia en la administración contemporánea de las ciudades, por su lugar privilegiado como referente de los discursos políticos y las intervenciones urbanísticas. El espacio público se ofrece politizado, ideologizado: al mero vacío generado en torno a toda edificación se le suma la urgencia de su gestión útil y moral; es un espacio que representa algo de la gente que lo utiliza y, para la gente que lo utiliza, es un espacio sexuado (Langarita, 2013; 2015), ideológico (Delgado y Malet, s. f.; Delgado, 2015), que no puede comprenderse sin referencia a los valores imperantes en la sociedad que lo planifica, usa y piensa o a los procesos que han hecho de él el signo de la salud democrática (entendida como estética, como imagen apetecible para el libre fluir de las inversiones, un incentivo para el capital).

Pero la producción del espacio público no es unilateral: en la medida en que su producción, disposición y práctica nunca es apolítica, tampoco resulta indiferente; el discurso crítico, la práctica disidente, la apropiación del espacio con fines políticos, reformadores, revolucionarios o, sencillamente, de goce ilícito son a un mismo tiempo objeto y finalidad de los estudios de antropólogos, geógrafos críticos, filósofos, sociólogos, etc.

En este sentido, atañe al presente ensayo el plexo de problemas relacionado con la significación y la normatividad del espacio público, por mediación de las prácticas, los discursos y las expectativas y proyecciones (morales, económicas o de cualquier tipo) de sus usuarios y otros agentes involucrados. En otras palabras: pretendemos ocuparnos aquí de cómo se produce y comprende la publicidad del espacio público y de cómo dicha producción y comprensión repercute normativa y performativamente sobre los usuarios de aquel. Sin embargo, el enfoque que hemos escogido pretende comentar estos aspectos con la ayuda de las etnografías que se han venido realizando en los últimos tiempos sobre el cruising, por cuanto esta actividad, que implica una apropiación furtiva de determinados espacios públicos para el desarrollo de actividades sexuales anónimas entre hombres (Blanco y Ugena, 
2014; Langarita, 2013; 2015; Rojas Herra, 2016), ofrece un observatorio privilegiado del desfase entre el espacio público como dispositivo performativo y los agentes, que no siempre son meramente moldeados por tales dispositivos, que no siempre operan como reproductores del dispositivo -al modo en que lo harían engranajes bien engrasados-, sino que pueden llevar a cabo en él prácticas disidentes o resignificaciones sigilosas.

Nuestra investigación ofrece así un marco teórico y conceptual para el análisis del espacio público en general y del cruising como práctica límite en y del espacio público, así como una primera tentativa de aplicación capaz de mostrar lo fructífero tanto del objeto como del método de análisis. Tomando en consideración el espacio público como algo que se produce a distintos niveles, interrogamos aquí dispositivos variados: desde ordenanzas (Barcelona, Bilbao, Badajoz y Madrid, como ciudades a un mismo tiempo ejemplares y de diversa configuración histórica, urbanística, económica...) hasta discursos públicos en diversos medios de comunicación y el sentido de la distribución arquitectónica de la visibilidad. Para la delimitación del cruising como objeto de análisis teórico y etnográfico relevante, el presente artículo recoge las distintas perspectivas desde las que ha sido estudiado y propone nuevos horizontes de análisis, subrayando la importancia de investigar el potencial crítico-político del cruising en cuanto práctica subversiva de producción del espacio público.

\section{MARCO TEÓRICO Y ESTADO DE LA CUESTIÓN}

El espacio ha de ser analizado desde las diferentes formas de positividad que ofrece, de forma que se pueda registrar no solo la manera en que este orienta y limita materialmente las acciones, la mirada o la atención de los usuarios, sino también aquella otra en que orienta y limita simbólica y significativamente la acción y la atención, proyectando sobre el espacio todo el campo de lo posible, lo correcto, lo eficiente, lo bueno y sus contrapartes. Se busca la unidad de sentido de fenómenos dispares: prohibiciones explícitas, gestión de la luminosidad, disposición de la vigilancia telemática o presencial, separación clara y distinta del espacio según usos pautados, distribución de zonas de reposo y zonas de tránsito, trazado de los caminos, apropiaciones furtivas de los recovecos, aprovechamiento de los imprevistos, resignificación y contrasignificación. Para ello, hemos encontrado necesario recurrir al 
aparato conceptual de génesis foucaultiana (centrado en la noción de dispositivo) y al de Henri Lefebvre (en torno a la producción del espacio).

La noción de dispositivo es imprescindible para localizar y conceptualizar conjuntos articulados de elementos simbólicos y materiales capaces de orientar la subjetivación en un sentido, pero también susceptibles de reapropiación para nuevos (y quizá contrarios) fines. Usada profusamente por Michel Foucault $(1975 ; 1976)$ y tematizada por Deleuze (1990), Chignola (2016) o Villacañas (2016), entre otros, expondremos concisamente qué es un dispositivo para nosotros, de cara a esclarecer el uso que haremos de este concepto a lo largo del ensayo: un dispositivo se compone de positividades simbólico-materiales dispuestas para un fin concreto (pues responden a urgencias), pero cuyos efectos y usos, en cuanto desplegados en tiempos y espacios diferentes, jamás pueden ser previstos a la perfección. Tales dispositivos poseen un carácter semitrascendental: surgen de la concreción de lenguaje, vida y trabajo (Foucault, 1968) y, como tales, ejercen de condición de posibilidad del (re)conocimiento; en este sentido, su alcance ontoepistémico y ético implica la generación de comportamientos, taxonomías (las más de las veces, morales), identidades y significados.

Cuando los dispositivos se integran en (y dependen de) este espacio público, en el que los usuarios son conducidos, reflejados, reconocidos, a sí mismos y entre sí, su estudio no puede evitar observar la tematización que del espacio desarrolló Henri Lefebvre. El espacio público en cuanto dispositivo cobra nueva luz con la tríada de conceptos que elaboró en La producción del espacio: práctica del espacio, espacio de representación y representación del espacio (Lefebvre, 2013: 92, 97 y ss.). El primero alude al espacio en cuanto terreno de las acciones cotidianas, lo recurrente, lo típico y lo normal. El espacio de representación, en cambio, remite al complejo entramado simbólico que torna significativo el sistema de objetos, construcciones y signos, en cuanto es vivido por los usuarios, esto es, en cuanto que les afecta efectivamente, en cuanto los usuarios lo hacen suyo o lo rechazan: es este un espacio en puja, donde prácticas y contraprácticas, discursos oficiales y reformulaciones activistas, filosóficas y artísticas luchan por imponerse. Por último, la representación del espacio es el entramado simbólico hegemónico, aquel que, sin ser el espacio percibido del uso cotidiano, ni el espacio de representación, quiere en todo momento ser uno y otro, asimilarlos mediante discursos oficiales, modificaciones dirigidas del espacio y un largo etcétera de mecanismos concretos, siguiendo las pautas dictadas por el sistema dominante. Además, nuestra reflexión ha intentado insistir sobre el efecto 
performativo de la cotidianidad mediada por este espacio público en el que, en los límites de la indiferencia, todos somos jueces y juzgados.

En cuanto al cruising, desde que en 1970 Laud Humphreys publicase Tearoom Trade. Impersonal Sex in Public Places, que constituyó la primera monografía sobre el sexo anónimo en Estados Unidos, numerosos antropólogos se han interesado por esta práctica. Originalmente, el trabajo de Humphreys adolece de un importante sesgo moral que le obliga a acercarse a él en cuanto «conducta desviada encubierta»; esta circunstancia suscitó un extenso debate en torno a la ética del investigador y al correcto análisis y tematización de los objetos de estudio que dio a parar en la publicación en la revista International Journal of Sociology and Social Policy (Schacht, 2004) de un monográfico que examinaba pormenorizadamente la investigación de Humphreys. Podríamos afirmar, por lo tanto, que desde un inicio el cruising se muestra como una práctica con una carga política y moral significativa, digna de análisis antropológicos y sociológicos. No obstante, el trabajo de Humphreys comienza a vislumbrar algunos aspectos fundamentales, como el papel de los actos sexuales en la constitución de identidades, mostrando que no se podría hablar tanto de homosexuales como de «participantes en actos homosexuales» (Humphreys, 1975 [1970]: 18). También indaga en el funcionamiento de las zonas de cruising y las demandas principales de quienes lo practican.

Con la aparición del VIH, la mayoría de las investigaciones se han orientado a una mejora de los programas de prevención. Algunas de las aportaciones internacionales más reseñables a este respecto serían las de Huber y Kleinplatz (2002), quienes se esmeran en desentrañar la forma en que los participantes del cruising construyen su identidad sexual para comprobar si puede tener alguna relación con que tomen menos precauciones a la hora de mantener sexo, Michael Reece y Brian Bodge (2004), centrados en el impacto sobre la salud de la práctica del cruising en el entorno estudiantil, y Paul Flowers, Graham Hart y Claire Marriott (1999), cuyo estudio analiza la percepción de los riesgos por parte de los usuarios de las zonas de cruising. En el ámbito nacional, Fernando Villaamil y María Isabel Jociles (2008), así como la reciente tesis doctoral de Fernando Lores (2012) se enmarcarían dentro de estos estudios del cruising que enfrentan el problema de sus repercusiones sobre la salud. Otras publicaciones etnográficas recientes al respecto serían las de Luis Alonso Rojas (2016), Berta Blanco y Sofía Ugena (2014), Guillermo Pozo (2017), Fernando Ramírez Arcos (2013), Francisco Javier Dóniz Páez (2014), Arantxa Grau (2015) y, principalmente, la de José Antonio Langarita 
(2015; 2013), cuya etnografía posee un carácter mucho más integral, orientándose tanto al problema de la construcción de identidades como al de las formas de comunicación, tanto al estigma social como a las dinámicas sociales que se establecen en las zonas de cruising, con su componente de género, de clase y racista [fruto de lo que Philippe Bourgois (1988) llamara «opresión conjugada»], tanto a la configuración de una homonorma mediada por el neoliberalismo como a la configuración ideológica del espacio público.

Nuestra investigación, si bien toca tangencialmente muchos de estos elementos, retoma la pregunta por la inscripción problemática del cruising en un espacio público previamente configurado ideológicamente y su potencial crítico-político.

\section{EL ESPACIO PÚBLICO}

El espacio público es intrínsecamente problemático. En cuanto concepto, pretende ser más que mero suelo. Hablar de espacio, expone Manuel Delgado, en el contexto de producción neocapitalista acaba siendo poco más que un eufemismo: «en realidad se quiere decir siempre suelo» (Delgado, 2015: 8). Pero ese suelo incluye un proyecto civilizante. Es algo más que suelo: es suelo diseñado, redefinido, hecho dispositivo. Esta redefinición parte de una cierta abstracción que lo torna permeable a un determinado tipo de discursos, maleable según las necesidades de los usos y los proyectos en que se inscribe. Un indicador de dicha abstracción es el uso del singular. Pese a que autores como José Antonio Langarita reclamen el uso del plural (Langarita, 2015: 16), la realidad es que el espacio público en su uso como concepto tiene mayor calado en singular. En toda la Ordenanza para preservar la utilización del espacio público en Badajoz y poblados, del ofrecimiento y demanda de servicios sexuales (2013) solo encontramos cuatro veces el uso del plural espacios públicos, frente a cuarenta y cuatro usos en singular. Igualmente, en toda la Ordenanza del espacio público publicada en el Boletín Oficial de Bizkaia (2010) hallamos doscientos cuatro usos en singular frente a veinticuatro en plural. Los espacios quizá deberían tener fines, motivos y disposiciones distintos, pero el espacio público tiene un uso discursivo casi universal, que exige ser enlazado con valores igualmente universales: la incuestionabilidad del espacio público y de su importancia va de la mano de la incuestionabilidad de los valores que encarna y resguarda. En este punto, el concepto bebe de otros supuestamente igual de universales e igual de importantes en la encarnación de valores inamovibles e 
incuestionables: se le relaciona con la dupla público/privado, pero también con la democracia clásica y con la moderna; toma como modelo al individuo liberal, pero admite sin reservas remitir a lo social, a la democracia como modo de vida, etc. Gracias a su abstracción, el concepto de espacio público puede nutrirse de imaginarios, valores o discursos dispares o incluso contradictorios. Tal es la eficiencia de su construcción preferente en singular.

También hemos de tomar en consideración su génesis reciente, el hecho de que, pese a referir en su uso y definición a elementos de calado histórico, su génesis como concepto es tardía y depende de unas condiciones sociopolíticas y económicas concretas, que podríamos enmarcar dentro de las últimas décadas de urbanismo neoliberal. Así, dice Manuel Delgado, el concepto aparece al servicio de la reapropiación capitalista de la ciudad: gentrificación, turistización de la historia, dispersión fallida de la miseria y también la gestión autoritaria de determinados segmentos de suelo (plazas, zonas peatonales comerciales...) que, se supone, darán la cifra de nuestra democracia y calidad de vida en un contexto de city marketing desaforado, al tiempo que, paradójicamente, el Estado del bienestar va abandonando la escena y los derechos democráticos básicos pierden gran parte de la protección con la que contaban (Delgado, 2015: 8-9).

Así, dividiremos el análisis del espacio público según las formas de lo público: esfera, espacio y vivencia.

\subsection{Lo público: esfera (ciudadanía y género)}

La gran dicotomía de lo público y lo privado ha abarcado contextos varios y usos políticos dispares y ha encontrado lugar en discursos de todo tipo. Lo público adjetiva espacios y esferas, es sustantivado o substancializado, describe y normativiza, pero es necesario enfocar el aspecto contingente, histórico y político del trazado (conflictivo) del límite entre lo público y lo privado.

Estos conceptos con función ontológica (pues dividen la realidad ideal en dos polos irreconciliables que ven sus formas híbridas mundanas marcadas por sus efectos) han conservado, según Nora Rabotnikof (1993), al menos tres sentidos que supuestamente los hacen herederos de la Grecia clásica y el derecho romano. En sus genealogías se remite a la distinción clásica entre esfera doméstica, que se encarga de necesidades básicas, humanas y familiares, y la esfera pública, «ámbito de la ciudadanía libre para el tratamiento debatido de asuntos comunes» (Rabotnikof, 1993: 76). A partir de dicha 
remisión se deducen ciertos sentidos: lo público sería lo que es de interés o utilidad común, de la comunidad y de sus autoridades (contraponiéndose a aquellos aspectos de incumbencia individual); sería lo visible, lo que se desarrolla a plena luz del día (a diferencia de lo oculto, lo intramuros); sería, además, lo que es de uso común (Rabotnikof, 1993: ibíd.). Otros aspectos parecen haber ido sedimentando en él: su relación con un predominio de la palabra frente a otras formas de poder, siendo así la esfera pública el lugar para la argumentación, la discusión y la persuasión; su cercanía con una espacialización del concepto que lo muestra desde imágenes como el ágora, el foro, la plaza o el café; su relación con la construcción de la identidad ciudadana en cuanto igualdad de todos ellos ante la ley; la legitimidad de un control público sobre las creaciones y magistraturas que se den en lo público y, por último, la idea de una ley escrita, que limite el arbitrio individual.

Con la Ilustración, la esfera de lo público fue sinónima del ejercicio público de la razón, que habría de llevar a la anulación del conflicto por medio de la universalidad de sus dictados, al tiempo que la publicidad de todo lo que es común y colectivo, como imperativo, exigía la visibilización de todos los instrumentos del Estado. En la base de estas exigencias se encuentran el ciudadano y sus derechos.

En la concepción ilustrada de las esferas pública y privada, dicha dicotomía delimita las competencias del Estado, la sociedad (como conjunto de individuos) y los individuos singulares, apelando a la ley, a la moral y a los derechos, y a un imperativo de visibilidad de todo lo que no sea exclusivamente privado.

No obstante, ciertas genealogías feministas de las últimas décadas han demostrado que dicha tendencia a la espacialización incluye la naturalización de esta opresión. La génesis patriarcal de la dicotomía público/privado identifica lo privado con lo doméstico y lo doméstico con el lugar de la mujer, encargada de la reproducción (siendo lo público el lugar de la producción). En este sentido, la mujer no tiene voz ni voto y se asemeja a una propiedad del marido. Mientras este pertenece por igual a la esfera pública y a la privada, dominando en las dos, la mujer tiene su lugar legítimo bajo el techo del hogar, donde nunca será dominante, aunque pueda desarrollar un sentir semejante (Pateman, 1996). La ley, la moral y los derechos del ciudadano poseen así un marcado sesgo de género en la génesis del concepto, que solo recientemente ha perdido algo de fuerza.

El género se cifra de forma particular en el espacio público contemporáneo, ya plenamente reconceptualizado pero aún heredero de esta 
gran dicotomía. Así, no solo las mujeres no se han incorporado aún en igualdad de condiciones al mundo del trabajo, y aún resiste la naturalización y la justificación esencialista o biologicista de muchas de las violencias ejercidas hoy día en nombre del género, sino que el mismo espacio, en su condición urbanizada, simbólica y significativa, configura, corrige y reprime los cuerpos según patrones de género.

\subsection{Lo público: espacio (convivencia y prevención)}

En el contexto del urbanismo neoliberal el concepto de espacio público prolifera sin remisión al problema del Estado centrándose más bien en el «modo de vida» democrático (Delgado y Malet, s. f.) que se ha de desarrollar sobre el suelo así calificado. Dicha ausencia de remisión al problema del Estado parece responder no a su desaparición, sino a su resituación como gestor de poblaciones mediante dispositivos securitarios y biopolíticos que no disminuyen su acción represiva, sino que la redistribuyen y maquillan.

A los análisis foucaultianos sobre la «política social» del neoliberalismo (Foucault, 2007), se suma la incentivación del libre flujo del capital por medio de la creación de espacios atractivos para la inversión, de la proliferación de espacios no conflictivos, característicos, distinguidos: lugares con encanto, vanguardistas, terciarizados y únicos en su especie. El espacio público como elemento estratégico de primer nivel, tiene...

...la tarea estratégica de ser el lugar en el que los sistemas nominalmente democráticos ven confirmada la verdad de su naturaleza igualitaria [...] se quiere reconocer como espacio dispuesto, visibilizado, aunque sea a costa de evitar o suprimir cualquier emergencia que pueda poner en cuestión que ha logrado ser efectivamente lo que se esperaba que fuera (Delgado, 2015: 37-38).

Para comprender este proceso de estetización democrática en que tan importante es sacar todo aquello que suponga un riesgo del espacio público como mostrar la materialización del igualitarismo, del ciudadanismo, en sus zonas más representativas (centros de ciudad, zonas comerciales o turísticas, plazas, parques), son fundamentales dos conceptos: convivencia y prevención. Son estos conceptos en disputa, cuya definición implica siempre un posicionamiento respecto a los mismos. Nuestro análisis se ha servido, por un lado, de ciertas ordenanzas sobre el espacio público, para ver cómo opera y 
qué puede esconder el concepto de convivencia en el marco legal, y, por otro, de los magníficos estudios de Sergio García y Débora Ávila (2013, 2016) en torno a los dispositivos securitarios. ${ }^{1}$

Son paradigmáticas las páginas 6 y 7 de la ordenanza sobre usos del espacio público de Bilbao:

Es el momento de establecer determinaciones normativas que preserven el espacio público como lugar de convivencia ciudadana y del secular civismo demostrado [...] Esta actividad municipal potenciadora de los valores cívicos se ha de traducir necesariamente en la consecución de una ciudad más amable y agradable tanto para los vecinos y vecinas como para las personas que nos visiten y en una mayor calidad de vida de la ciudadanía al disfrutar de un espacio público de calidad, en todo momento dispuesto para el mejor disfrute de la ciudadanía, haciendo realidad con ello el natural destino de tal espacio público. En este ámbito del Uso Común en el que nos encontramos, que como ya se ha dicho acapara la mayor consideración municipal como espacio de convivencia y realización ciudadana en el que el uso y disfrute colectivo esté asegurado en condiciones de tranquilidad, seguridad, accesibilidad y todas aquellas otras condiciones que aseguran el estado óptimo del mismo, conviene establecer unas mínimas determinaciones relativas a usos que no son del gusto de la ciudadanía por los perniciosos efectos que ellos tienen para el uso común. [...] (Ordenanza del espacio público, 2010: 6-7; la cursiva es nuestra).

Por un lado, tenemos la repetición hasta la saciedad (idéntica en las ochenta páginas restantes) de ciertos referentes: convivencia y civismo. Su falta de determinación y la repetición son indicadores de su valor retórico. Ambos conceptos son revestidos de necesidad y urgencia por su preservación. Ambos conceptos, además, se relacionan con otros de los más valorados en el léxico político-social contemporáneo: calidad (del espacio, de uso, de vida), disfrute, ciudadanía (como realización, como esencia, como valor), tranquilidad, seguridad o accesibilidad. Ambos conceptos, además, si bien se consideran en peligro, se presentan como propiedades de la generalidad de los ciudadanos, lo normal, algo que simplemente hay que preservar, nunca que crear (algo asegurado y a asegurar). Este esqueleto abstracto de universalidad (Delgado, 2015: 48) opera sobre los usuarios una moralización democrática (la democracia como conjunto de valores irreprochables pero, en su extremo, vacíos de contenido) a cambio de una despolitización de los

1 Los dispositivos securitarios no se identifican con el espacio público en cuanto dispositivos, pero sí que resultan imprescindibles para configurarlo de tal manera. Podemos seguir a Sergio García en su definición de los dispositivos securitarios como «el conjunto de instituciones, arquitecturas, discursos y prácticas que configuran la "seguridad ciudadana" como uno de los problemas político-culturales fundamentales de nuestro tiempo a nivel glocal» (García, 2012: 573). 
mismos, que torne sus intervenciones políticas sobre el espacio público poco más que en una fiesta de los sentimientos democráticos, inocua para la capitalización del espacio y el mantenimiento de las desigualdades sociales que la posibilitan (Lefebvre, 2013: 370-373; Delgado, 2015: 32).

Igual que la repetición ha revelado el esqueleto abstracto, la no repetición de un motivo puede delatar su importancia: lo fundamental es hacer de la ciudad un lugar agradable de visitar para quien cumpla el modelo de ciudadano que se predique. Lo fundamental es, para hablar con el vocabulario de Lefebvre, que todo el suelo reciba valor de cambio (Lefebvre, 2013: 370; 1976: 67). Ahora bien, en este ideario la ciudad será tanto más amable cuanto más previsible sea, cuanto más tranquilidad, seguridad y accesibilidad (para el libre ejercicio del comercio) ofrezca. Se exige una estetización de la democracia: la democracia se muestra en la encarnación alegremente capitalista de sus espacios públicos, «fiel reflejo del alma de la ciudad», que coincide con el «natural destino» (Ordenanza del espacio público, 2010: 6-7) del espacio público (un tipo de espacio que, hemos mostrado, ni es ahistórico ni ningún destino le es innato).

La lógica que posibilita y legitima esta coordinación entre la mano izquierda (de los derechos, la democracia, el uso libre, los educadores de calle, dinamizadores de parques y espacios públicos, mediadores) y la mano derecha (de la represión, la intimidación y el lavado de cara forzoso de los espacios públicos) se apoya en un tipo de discurso cuyos conceptos articuladores son el riesgo y la prevención. Es notorio que no se habla tanto del riesgo que corre una persona en riesgo (riesgo de exclusión, de violencia, de precariedad) por las condiciones sociales en que se encuentra, sino del riesgo que esa persona supone para el resto, para el sano, normal, natural disfrute del espacio público por parte de los usuarios cívicos (García y Ávila, 2013: 69).

A su vez, entre los elementos conformadores de lo que se ha venido llamando prevención —en relación directa con la noción de riesgoencontramos algunos particularmente útiles para analizar las características del espacio público en cuanto dispositivo. Tales elementos, aparte de la estetización de las fuerzas del orden, serían, por una parte, el fomento de la participación ciudadana y la comunicación $y$, por otra, la producción de ambientes. Los dos primeros refieren a la implantación de una «cultura de la proactividad en el abordaje de un área de intervención ajena a la legalidad: la convivencia» (Boletín oficial de la provincia de Barcelona, 2011), concepto recurrente en nuestro análisis. Por otra parte, los espacios en que los usuarios puedan ejercer a un mismo tiempo de vigilantes y salvaguardas del buen hacer 
y el convivir han de ser creados. Se fomentan así, en el espacio público, regímenes de visibilización máxima, donde poder ver $\mathrm{y}$ ser visto. Según Manuel Correa, director del Observatorio de la Seguridad de Madrid: «Ver y ser visto por otros tranquiliza a los ciudadanos e inquieta al delincuente» (García y Ávila, 2016: 72). Se trata, pues, de disponer de espacios diseñados arquitectónicamente para ofrecer la mayor visibilidad posible, reducir la conflictividad social -o aumentar la sensación subjetiva de seguridad- e incentivar el flujo sin obstáculos de personas y capitales. Se tomarán medidas más represivas, por otra parte, contra aquellos mendigos, prostitutas, etc., que no hayan tenido a bien irse tras ser expuestos (medidas justificadas, entre otras formas, gracias a los procesos de patrimonialización de determinadas zonas por medio, por ejemplo, de la incentivación del arte en ellas) (Blanco y Ugena, 2014: 649).

\subsection{Lo público: vivencia (cotidianidad)}

A lo largo de su vida, Lefebvre invirtió mucho tiempo en tematizar el concepto de cotidianidad. Este concepto tendría que condensar lo propio del desenvolverse humano, siendo aplicado al contexto del mundo urbano. Su utilidad analítica reside justo en acoger bajo una sola noción tanto la realidad de la performatividad de los dispositivos como el desfase ineludible entre el dispositivo y la subjetividad por él dispuesta que, aprovechando la falibilidad de los primeros y la creatividad de los segundos, guarda siempre la posibilidad de la disidencia, de la creación, de la polémica, de la política o de la poesía. A su vez, la voz cotidianidad muestra la faceta vivencial de esta realidad, que tiene lugar en espacios de representación concretos, donde el mundo no es nunca el que nos han contado, pese a que los efectos de tales narraciones no cesen nunca de operar. La cotidianidad se vive como aburrimiento y como libertad, como deseo y como necesidad, como incapacidad y como posibilidad, y el sentir -el vivir algo de una determinada manera - tiene valor explicativo.

Así, lo cotidiano consta, para Lefebvre, de ciertos instrumentos y mecanismos ideológicos controlados de arriba abajo para la producción de una alienación general, pero justo sobre este adalid conceptual de la alienación se ejecuta la actividad crítica del filósofo, convirtiéndolo en signo no solo de la alienación, sino también de su posible superación. 


\subsection{Heteronormatividad y vigilancia}

Quizá su apuesta por una práctica poiética crítica del espacio peca de optimista, pero no es menos cierto que nos otorga la clave para comprender la eficiencia de la orientación reciente de los dispositivos neoliberales. Lo que siempre fue una exposición espectacularizada (Lefebvre, 1978: 95), ahora parece tornarse en muchos casos en una exposición comprometida, vigilante. $\mathrm{Al}$ anular estéticamente la oposición entre las fuerzas del orden y el cuerpo de los ordenados, convirtiendo a los usuarios legítimos en garantes del buen hacer y del buen aspecto del espacio público - al fomentar la participación ciudadana y el derecho a no ser molestados por la cara amarga del neoliberalismo-, los usuarios legítimos ya no acuden a la calle en calidad de espectadores y espectáculos, sino en calidad de vigilantes y vigilados potenciales. La lógica del riesgo y la prevención, incorporada en sus vidas, sus discursos, sus prácticas, sus valores y sus identidades, conlleva una facilidad para el reconocimiento de los indicadores hegemónicamente establecidos del riesgo y para la reacción preventiva individual u organizada. El poder se estetiza, se disimula, se dispersa (sin cancelar la mano derecha de la represión directa y menos sutil) y compromete a todos los usuarios legítimos, los buenos demócratas, la masa bienpensante de vecinos preocupados, mermando el potencial poiético y subversivo de la cotidianidad. Solo así podemos comprender casos como el sucedido en Dinamarca, donde un nuevo dispositivo securitario aparece allí donde no se tienen pruebas suficientes para juzgar a un vecino por yihadismo y traición: son los propios vecinos los que alertan a la policía para que se pongan en marcha las medidas necesarias para «prevenir la deriva hacia el extremismo y reintegrar en la sociedad a individuos radicalizados» (Medina, 2018). Aquí, el antropólogo no puede sino preguntarse qué pueden esconder términos como invitar, canalizar su indignación, encauzar su vida, etc.

Nos gustaría destacar una característica más del espacio público, tangencial a todas las anteriores, que entronca con el problema de lo público y lo privado en clave de género. Antes de analizar el fenómeno del cruising hay que destacar que el espacio público es un espacio heteronormado, donde la opresión (y con ella la conducción, la delimitación de lo lícito, la composición de lo posible, etc.) se determina a partir del modelo heterosexual de pareja chico-chica. La magnífica genealogía que José Antonio Langarita ha realizado muestra cómo la imagen del homosexual se ha venido asociando en la 
modernidad (y en concreto en España), mediante la puesta en marcha de dispositivos discursivos, científicos y legislativos, a las mayores perversiones, desviaciones morales y delitos, formando parte de un imaginario que también han sufrido inmigrantes, clases bajas y mujeres alejadas de la feminidad hegemónica. De esta forma, el homosexual es susceptible de detonar mecanismos preventivos, quizá no institucionalizados, pero sí interiorizados, incorporados, en cuanto indicador de riesgo de conductas ilícitas, incívicas o inmorales. Más aun, con el surgimiento del VIH, la figura del homosexual entra por derecho científico dentro de los mecanismos de prevención de riesgos cuyos efectos hemos dilucidado superficialmente, individualizando la responsabilidad y desenfocando sus condicionantes sociales.

Por supuesto, no todo es blanco o negro. Aquí ayuda comprender la naturaleza de la opresión conjugada que se ejerce sobre determinados sectores de la población: el homosexual puede conquistar una situación de respeto en determinados espacios públicos si pone en acto comportamientos que le muestren cumpliendo (en la medida de lo posible) el ideal heterosexual de pareja (larga duración, exclusividad sexual, expresiones de afecto no sexuadas) y el ideal neoliberal de consumidor (clase media-alta y clase alta, estética cuidada, aspecto saludable, cliente en locales nocturnos y zonas comerciales). Medallas para los estetas de la democracia. Por supuesto, no podrán decir lo mismo de los homosexuales inmigrantes, sin papeles, sin dinero o con VIH (Langarita, 2015: 54).

Por su parte, la vigilancia y la represión contundente de aquellas conductas viciosas, que manchen la imagen del buen homosexual (el homosexual conveniente para la buena imagen de la ciudad y el incremento del valor de cambio de su suelo), serán anunciadas como un logro y celebradas públicamente. Tal es el caso del alcalde de Badalona, Xavier Albiol, que expone tranquilamente su estrategia de distribución jerárquica de la moralidad según convenga a la imagen de la ciudad: en el centro, convivencia, recato; en la periferia, nudistas normales; en las dependencias policiales, los viciosos (ACN, 2012). 


\section{ESPACIO PÚBLICO Y HETERONORMA EN LA EXPERIENCIA DEL CRUISING}

De acuerdo con el análisis desplegado sobre el espacio público y las herramientas e ideas recogidas en el mismo, es nuestra intención desarrollar ahora un pequeño estudio focalizado sobre el fenómeno del cruising, por cuanto nos permite atender, en un mismo conjunto de prácticas sobre el espacio público, la relación entre determinados dispositivos securitarios y el proceso de estetización de la democracia, promocionando un espacio público previsible, decoroso, decorado y primariamente heterosexual, por medio de la aplicación de violencias sutiles o explícitas, según se dirijan a unos sectores de la población o a otros.

El cruising carga con un profundo estigma social. Quienes lo practican aprecian sobre todo su anonimato, sus prácticas se llevan a cabo en un casi absoluto silencio $y$, además, tienen una corta duración, variando constantemente el flujo de practicantes a lo largo del día. Esto hace que el cruising sea particularmente difícil de etnografiar (Dóniz Páez, 2014: 3). Ahora bien, el silencio autoimpuesto implica la necesidad de una interacción creativa con el espacio y los cuerpos que posibilite la comunicación, y el estigma (o los estigmas) que se dan cita permiten el análisis de las ideologías que los producen y las representaciones del espacio que les acompañan.

Diríamos que, de un espacio práctico bien delimitado con una representación del espacio marcada por las concepciones hegemónicas sobre el pudor, el pecado, el recato y el género, como son los baños públicos, el cruiser lleva a cabo una reapropiación o desviación (Lefebvre, 2013: 213-216) que, si bien su misma marginalidad y esfuerzo por el anonimato no permite que sea radical, sí que posee cierto potencial subversivo. Mientras el diseño ha dispuesto la práctica del espacio acorde con la representación hegemónica del mismo, conjugando objetos como cabinas cerradas (un obstáculo para miradas furtivas) cuyas puertas no alcanzan el suelo (una invitación a la vigilancia), urinarios con forma cóncava que ocultan los genitales y bloquean el deseo y grandes espejos que permiten un control del campo visual (casi una interpelación moral: observa a tus semejantes), el cruiser dispone en cambio de un espacio de representación, donde la potencia de uso del sistema de objetos se muestra distinta (Pozo Arribas, 2017): el espejo es óbice para contactos visuales, el hueco entre las cabinas y el suelo se torna conducto sigiloso para la transmisión de mensajes mediante signos pautados y silenciosos, el espacio íntimo y aislado creado dentro de las cabinas sirve para esperar a que se 
renueven los usuarios del baño público, así como para consumar las prácticas sexuales. En este sentido, la concatenación de interpelaciones de la que ha sido objeto el cruiser desde que se ha acercado al baño público obtiene una respuesta subversiva que transforma el espacio y confronta la moral en él inscripta.

No obstante, el cruising no logra anular el dispositivo que dicho espacio compone en cuanto articulación de representación del espacio y disposiciones materiales adecuadas. Esto puede deberse a que una práctica orientada únicamente a la satisfacción (legítima) del deseo carece del potencial de trascendencia que puedan tener el arte, la filosofía o la política, es decir, las prácticas destinadas a una transformación radical del objeto y, en el caso de las dos últimas, comprometidas social y éticamente con dicha transformación. ${ }^{2}$ No obstante, ciertas modificaciones no radicales del dispositivo de la sexualidad, especialmente en su aspecto discursivo e imaginario, permiten a gran cantidad de cruisers mantener y vivir una identidad heterosexual (es decir, no fingirla, sino sentirla y afirmarla) pese a la realización de actividades marcadamente homosexuales. Langarita ha destacado el elemento principal de esta variación del dispositivo de la sexualidad: el pene (y no el cruiser) como sujeto deseante cuyos deseos hay que conceder sin comprometer el resto del cuerpo (Langarita, 2015: 139). Esta deriva logra una reconciliación personal del cruiser con su género y con los privilegios que este conlleva (privilegios que no pone en riesgo más de lo debido, gracias a la preponderancia del anonimato y el silencio).

Por supuesto, hemos hablado de los baños públicos y de la forma en que su diseño típico busca poner en acto el sistema de valores orientando gestos, promoviendo conductas, impidiendo acciones impúdicas, etc. Sin embargo, cabe destacar que, cuando tales sutilidades no impiden la apropiación del espacio público, no se escatiman recursos:

Las dársenas se distribuyen a izquierda y derecha del intercambiador de Plaza de Castilla. En el último pasillo del último piso, en la parte más recóndita y solitaria del lugar, hay unos baños públicos. Y a la entrada, un vigilante muy alto apoyado en la pared. (Borasteros, 2009)

\footnotetext{
Aunque su desarrollo en ciertos lugares altamente polémicos puede potenciar su carga política: pongamos el caso del cruising en el Parque Nacional de San José (Costa Rica), etnografiado por Luis Alonso Rojas (2016), zona para nada marginal, rodeada de varias instituciones gubernamentales y edificios emblemáticos.
} 
No sirven menos al mantenimiento de la estabilidad socio-sexual las agresiones en transportes públicos, multas a prostitutas, insultos a los amanerados, la expulsión de los locales, etc. (Langarita, 2015: 100). Podemos notar cómo, de hecho, un cierto discurso justificativo de las agresiones a quienes presenten conductas desviadas está presente en la opinión pública. Por ejemplo, ante una noticia cuyo titular reza «Un grupo de gays, agredido en una zona de cruising de Madrid al grito de sidosos» (Vera, 2017), los comentarios se dividen: aproximadamente la mitad acusan a la extrema derecha o aprovechan la ocasión para defender el Orgullo Gay, mientras otra mitad reproducen muchos de los tópicos ideológicos asociados al espacio público y a la heteronormatividad. Se responsabiliza al homosexual por las discriminaciones y agresiones que sufre en la medida en que no quiera adaptarse al estándar de promiscuidad legítima (en casa y en locales comerciales habilitados para ello), promoviendo la imagen del buen homosexual, el homosexual respetable que se ajusta a los códigos heteronormativos y de clase social (Langarita, 2015: 181).

La cultura homonormativa adopta así todos los parámetros de la heteronormativa no concernientes a la orientación sexual, «dejando fuera otras formas de expresión sexual pública y construyendo espacios de consumo y gentrificación urbana» (Langarita, 2015: 106). Como blasón de la democracia encarnada, de su libertad, convivencia, tolerancia y civismo, toda ciudad pasa a disponer de un barrio gay emblemático, facilitando la normalización y la generación de determinados tipos de homosexuales, pero también estimulando las discriminaciones a aquellos usuarios del espacio público que no se adhieran a la homonorma. Especialmente cuando, fruto de opresiones conjugadas, esta homonorma se determina por la posesión de un alto nivel adquisitivo, identificando en cierta medida al verdadero homosexual con el homosexual de clase alta.

Por otro lado, las etnografías reportan que, incluso en el contexto concreto del cruising, las distintas opresiones no se cancelan provisionalmente: Langarita se percata de que muchos de ellos, de origen pakistaní, se conforman con masturbarse observando, sin entrar en contacto con otros hombres. Igualmente, pobreza, inmigración, delincuencia y falta de higiene van de la mano, haciendo que sea de sentido común no mantener relaciones sexuales con ellos porque «los marroquíes vienen a robar» o porque «tienes que ponerte la mascarilla» para respirar su olor (Langarita, 2015: 192 y 193). 


\section{CONCLUSIÓN:}

Cuando Teresa Caldeira fijó su atención en un São Paulo presa de lo que 1lamó «estética de la seguridad» (2010: 118), su análisis fue de la mano del reconocimiento de una serie de prácticas transgresoras que, más allá de modificar el espacio, impugnaban la realidad de desigualdad que reviste dicho espacio. El grafiti y la pichação aprovechaban la solidez de los muros para resignificarlos, convirtiéndolos en espacios de comunicación en lugar de espacios de separación (Caldeira, 2010: 120), reivindicando con ellos el derecho a la ciudad.

Hemos notado que en las ciudades españolas se promueve una conceptualización y un diseño del espacio público en el que las diferencias sociales, la ideología de género y cierto tipo de racismo se generan, promueven, mantienen y significan mediando primeramente otros mecanismos. Así como la pichação cobra plena operatividad y sentido en un entorno marcado por dispositivos de seguridad sólidos, con su consecuente separación radical de espacios, mostrando la tensión entre espacio práctico, espacio de representación y representación del espacio, el cruising cobra pleno sentido crítico allí donde el espacio se configura por medio de dispositivos fluidos, cuya estética preferente no es la del muro, sino la de la convivencia y el civismo, y donde la interpelación de género reviste el lenguaje del espacio. La comparación con los análisis de Teresa Caldeira muestra en qué medida la determinación de la representación del espacio y los espacios de representación en disputa es bidireccional; así se configuren los dispositivos de producción de representación del espacio, así se configurarán las disidencias, y viceversa. Es cierto, por otro lado, que pichação y cruising no pueden ser analizados bajo una misma óptica: los primeros tienen una finalidad política consciente, mientras que el potencial político del segundo queda sin uso en la mayoría de los casos.

En este sentido, el cruising ha mostrado ser una práctica fructífera de analizar, por cuanto pone en evidencia la forma en que se conjugan algunas de las opresiones características de la democracia estética que se ha venido tematizando, así como una resignificación del espacio que, si bien no parece tener un uso crítico social, sí sirve de ejemplo paradigmático de la lucha de sentidos y significaciones que se da en todos los espacios y del potencial creativo del deseo, y que le dota, en cierta manera, de un potencial político inherente. Queda sin interrogar cómo el análisis filosófico y etnográfico pueda revitalizar ese potencial político. 


\section{BIBLIOGRAFÍA}

ACN (8 de agosto, 2012). Xavier Albiol promete "contundencia" y "presión policial" contra el 'cruising' en la playa de la Mora. El punt avui. Recuperado de:

http://www.elpuntavui.cat/article/3-politica/17-politica/566391-xavieralbiol-promet-contundencia-i-pressio-policial-contra-el-cruising-a-laplatja-de-la-

mora.html?piwik_campaign=rss\&piwik_kwd=nacional\&f=El+Punt + Av ui

Ayuntamiento de Badajoz (2013). Ordenanza para preservar la utilización del espacio público de Badajoz y poblados, del ofrecimiento y demanda de servicios sexuales. Badajoz: Instituto Municipal de Servicios Sociales.

Blanco, Berta y Ugena, Sofía (2014). Público-privado-punible: dinámicas performativas del espacio y la identidad a través del cruising. En Andreu Tomàs, Agustí, Badoque Puerta, Yolanda, Comas d'Argemir i Cendra, Dolors, Pujadas Muñoz, Joan Josep, Roca Girona, Jordi y Soronellas Masdeu, Montserrat (Eds.). Periferias, fronteras y diálogos: Actas del XIII Congreso de Antropología de la Federación de Asociaciones de Antropología del Estado Español (641-662). Tarragona: Publicacions de la Universitat Rovira i Virgili.

Boletín oficial de Bizkaia (27 de septiembre, 2010). Ordenanza del espacio público. BOB(186).

Boletín oficial de la provincia de Barcelona (17 de febrero, 2011). Ordenanza de medidas para fomentar y garantizar la convivencia ciudadana en el espacio público de Barcelona. Recuperado de: http://www.dpz.es/ficheros/documentos/ordenanzao1.pdf

Borasteros, Daniel (24 de noviembre, 2009). Tres estaciones con baños muy controlados Los guardas custodian los servicios para impedir el sexo entre hombres. El País. Recuperado de: https://elpais.com/diario/2009/11/24/madrid/1259065460_850215.html [Consultado el 17 de diciembre de 2017]

Bourgois, Philipp (1988). Conjugated oppression: class and ethnicity among guayi and kuna banana plantation workers. American ethnologist, $15(2)$, 328-348.

Caldeira, Teresa (2010). Espacio, segregación y arte urbano en Brasil. Buenos Aires: Katz. 
Chignola, Sandro (2016). Sobre el dispositivo. Foucault, Agamben, Deleuze. En Salinas Araya, Adán y Castro Orellana, Rodrigo (Eds.). La actualidad de Michel Foucault (169-184). Madrid: Escolar y Mayo.

Deleuze, Gilles (1990). ¿Qué es un dispositivo? En Varios autores. Michel Foucault, filósofo (155-163). Barcelona: Gedisa.

Delgado, Manuel (2015). El espacio público como ideología. Madrid: Catarata.

Delgado, Manuel y Malet, Daniel (s.f.). El espacio público como ideología. Recuperado

http://www.fepsu.es/docs/urbandocs/URBANDOC1.pdf

Dóniz Páez, Francisco Javier (2014). Territorio, género, homosexualidad masculina y sexo: los espacios de cruising en Tenerife. XXI Coloquio de Historia Canario-Americana, 1-7. Recuperado de: http://coloquioscanariasmerica.casadecolon.com/index.php/aea/article /view/9550

Flowers, Paul, Hart, Graham y Marriott, Claire (1999). Constructing sexual health. Gay men and "risk" in the context of a public sex environment. Journal of health psychology, $4(4), 483-495$.

Foucault, Michel (1968). Las palabras y las cosas. México: Siglo XXI.

Foucault, Michel (1975). Surveiller et punir. Naissance de la prison. Paris: Gallimard.

Foucault, Michel. (1976). La volonté de savoir. Paris: Gallimard.

Foucault, Michel (2007). El nacimiento de la biopolítica. Buenos aires: Fondo de cultura económica.

García, Sergio (2012). Dispositivo securitario en un espacio barrial: la práctica policial de los controles de identidad. ARBOR. Ciencia, pensamiento $y$ cultura, $188(755), 573-590$.

García, Sergio y Ávila, Débora (2013). Entre el riesgo y la emergencia: insinuaciones policiales en la intervención social. Revista de Antropología Social, 22, 59-82. doi:http://dx.doi.org/10.5209/rev_RASO.2013.v22.43184

García, Sergio y Ávila, Débora (2016). La prevención securitaria como modo de gobierno: el caso de Madrid. Athenea digital, 16(1), 43-82.

Grau, Arantxa (2015). Cruising y e-citas: un nuevo contexto para los encuentros sexuales entre hombres jóvenes que tienen sexo con hombres. Cuadernos de saúde pública. doi:10.1590/0102-311Xooooo215

Huber, Jonathan y Kleinplatz, Peggy (2002). Sexual orientation identification of men who have sex with men in public settings in Canada. Journal of homosexuality, $4_{2}(3), 1-20$. 
Humphreys, Laud (1975 [1970]). Tearoom Trade. Impersonal Sex in Public Places. New York: Enlarged.

Langarita, José Antonio (2013). Apropiaciones furtivas de espacios públicos: Intercambio sexual anónimo entre hombres en el entorno urbano. Quaderns-e, 18(1), 99-113.

Langarita, José Antonio (2015). En tu árbol o en el mío; una aproximación etnográfica a la práctica del sexo anónimo entre hombres. Barcelona: Bellaterra.

Lefebvre, Henri (1976). Espacio y política. Barcelona: Península.

Lefebvre, Henri (1978). De lo rural a lo urbano. Barcelona: Península.

Lefebvre, Henri (2013). La producción del espacio. Madrid: Capitán Swing.

Lores Masip, Fernando (2012). Deseo y peligro: anotaciones antropológicas a una teoría de la contaminación y de los cuidados sexuales. Tesis doctoral. Madrid: Universidad Complutense de Madrid.

Medina, Alicia (o4 de enero, 2018). Vecinos que vigilan al yihadista: el modelo contra la radicalización de Dinamarca. El Confidencial. Recuperado de: https://www.elconfidencial.com/mundo/2018-01-04/dinamarcayihadistas-vigilancia-terrorismo-siria_1501231/

Pateman, Carole (1996). Críticas feministas a la dicotomía público/privado. Barcelona: Paidós.

Pozo Arribas, Guillermo (2017). Mecanismos de producción y resignificación de los espacios de cruising en el siglo XXI. Trabajo fin de grado, tutorizado por Atxu Amman Alcocer. Madrid: Escuela técnica superior de arquitectura de Madrid (ETSAM).

Rabotnikof, Nora (1993). Lo público y sus problemas: notas para una reconsideración. RIFP, 2, 75-98.

Ramírez Arcos, Fernando (2013). Cuestionamientos a la geografía a partir del cruising entre hombres en Bogotá. Revista Latino-americana de Geografía e Gênero, 4(2), 134-147.

Reece, Michael y Dodge, Brian (2004). Exploring the physical, metal and social wellbeing of gay and bisexual men who cruise for sex on a college campus. Journal of homosexuality, 46(1), 111-136.

Rojas Herra, Luis Alonso (2016). Cruising: la apropiación fortuita del espacio público para mantener relaciones sexuales esporádicas entre hombres. Rupturas, 6(2), 329-344.

Schacht, Steven P. (2004). International Journal of Sociology and social policy (edición especial), 24. 
Vera, Joaquín (8 de agosto, 2017). Un grupo de gays, agredido en una zona de cruising de Madrid al grito de sidosos. El Español. Recuperado de: https://www.elespanol.com/reportajes/20170808/237476555_o.html\#co mments\&page $=2$

Villaamil, Fernando y Jociles, María Isabel (2008). Diferencias y desigualdades entre los HSH usuarios de locales comerciales de encuentro sexual: algunas contribuciones a las estrategias comunitarias de prevención del VIH. Etnográfica, 12(2), 285-321.

Villacañas, José Luis (2016). Dispositivo: la necesidad teórica de una Antropología. En Salinas Araya, Adán y Castro Orellana, Rodrigo (Eds.). La actualidad de Michel Foucault (185-212). Madrid: Escolar y Mayo. 